\title{
Presentación. «Mando se junten mis ministros». Las Juntas como herramientas de gobierno bajo los Austrias
}

\author{
Presentation. «l order my ministers to meet». \\ The Juntas as Tools of Government under the Habsburgs
}

\section{SYLVAIN ANDRE}

Sorbonne Université

Institut d'études ibériques et latino-américaines

CLEA (EA-4083)

31 , rue Gay Lussac

75005 Paris (France)

sylvain2.andre@gmail.com

FRANCISCO GIL MaRTÍNEZ

Universidad de Almería

Facultad de Humanidades

SURCLIO

Carretera Sacramento, s/ $\mathrm{n}$.

04I20 Almería (España)

franciscogil@ual.es

¿Llegaron las Juntas a constituir un sistema de gobierno y, de ser así, cuál fue la naturaleza de tal sistema? Estas son, quizá, las preguntas, subyacentes o fundamentales, que con más frecuencia se plantearon los historiadores que se han interesado por aquellos órganos de gobierno llamados «juntas». Este planteamiento era pertinente en la medida en que, inicialmente, aquellos que estudiaron las juntas asimismo estudiaban los Consejos, la polisinodia y, en general, el marco legal e institucional por el que se movía la decisión regia. Con frecuencia, desde la perspectiva de la historia de las instituciones — rama en cierto modo de la historia del derecho'-, las juntas llegaban a constituir de facto una anomalía,

\footnotetext{
I Tomás y Valiente, 1982.
} 
un sistema paralelo a la polisinodia, fuente de conflictos, cuando no cortocircuito de las vías legales de la consulta ${ }^{2}$. Alentada en parte por los discursos conservadores del siglo XVII en contra de las juntas, en parte confortada por unas fuentes difíciles de identificar y discernir en la documentación política de la monarquía, la historiografía sobre la Administración también ha tenido la costumbre de considerar el fenómeno juntista como una suerte de mal necesario, como un mecanismo al servicio de las arcanas del poder, como una manifestación, en suma, de la razón de Estado que se expresaba al margen, por no decir en contra del desarrollo burocrático de la monarquía ${ }^{3}$. Las aportaciones de estos trabajos son valiosísimas para el conocimiento de las áreas políticas en las que se desenvolvían las juntas, sea en el dominio militar ${ }^{4}$, hacendístico ${ }^{5}$, de la Casa Real ${ }^{6}$, etc. Pero por lo que atañe a las juntas como objeto histórico, parece evidente, a varias décadas de distancia, que la estructura jurídica en la que se insertaban o, si se quiere, a la que escapaban, no era ni podía ser un marco conceptual eficaz para aclarar las razones de la emergencia de esos órganos a finales del XVI y menos todavía las de su éxito a lo largo de la centuria siguiente.

Más tarde, la historiografía de las redes de patronazgo cambiaron el paradigma explicativo ${ }^{7}$. Observando que las juntas constituían un espacio privilegiado para el desarrollo de solidaridades y redes clientelares, los historiadores de la corte, en los años 1990, han subrayado otros aspectos del fenómeno. La velocidad de ejecución, la necesidad de recurrir a experto, la complejidad creciente de las vías de la decisión real en Madrid, permitieron renovar los interrogantes sobre unos colegios que seguían todavía careciendo de estudios sólidos. Este nuevo enfoque eliminó las limitaciones impuestas por el concepto de Estado moderno y abrió la puerta a una lectura más compleja del gobierno en la Época moderna ${ }^{8}$. No obstante, los disfuncionamientos y las perturbaciones jurisdiccionales que

${ }^{2}$ Larga sería la relación de trabajos que, voluntariamente o no, inducen esta lectura en la historiografía de los años 1970 e incluso 1980. En lugar de ofrecer aquí al lector una lista que no podría ser exhaustiva, daremos una prueba del hondo calado que tuvo esta percepción en el tiempo y que se encuentra en el libro relativamente reciente de Feliciano Barrios en el que explica que «la erección de muchas [Juntas], especialmente en el XVII, era una forma de superar el constreñido marco institucional que ofrecía el régimen de Consejos, respecto de determinadas actuaciones que pudieran resultar atentatorias contra la jurisdicción exclusiva de un Consejo; o bien su constitución era el modo de sustraer un negocio a un sínodo determinado que pusiera dificultades para su resolución [...] De esta manera, su utilización con criterios de oportunidad política sirvió frecuentemente para soslayar la vía conciliar ordinaria, no sin resistencia de los órganos afectados», cf. Barrios, 20I5, p. 411 .

${ }^{3}$ Gil Cremades, 197I; Bercuyo, 1983.

${ }^{4}$ Domínguez Nafría, 1988.

${ }^{5}$ Pelorson, 1983.

${ }^{6}$ Benito Fraile, 1994.

7 Martínez Millán y Carlos Morales, 1998.

8 Martínez Millán, 1992. 


\section{PRESENTACIÓN. «MANDO SE JUNTEN MIS MINISTROS»}

provocaban las juntas no dejaron de ser el pilar en el que se sostenía el edificio historiográfico sobre las juntas: de anomalía estructural, pasaron a ser escenarios de conflictos sociales, especialmente entre nobleza conciliar y élite letrada. De tal manera que, en muchas ocasiones, las juntas parecían antecámaras directas de la decisión real, lugares donde se cocían hasta los asuntos políticos más importantes entre familiares, clientes y grupos de poder reunidos más por razones personales que por el servicio del rey. Esta predeterminación de las juntas, es decir el hecho de ser por definición espacios de defensa de intereses particulares, arrojó una luz nueva sobre la sociedad de corte, pero redujo drásticamente la posibilidad de que emergieran del estudio de las juntas aportaciones en términos de funcionalidad gubernativa de la monarquía. De nuevo, aunque por otra vía, se llegaba de esta manera a la misma observación que antes: la cartografía de las redes de poder que articulaban las juntas era insuficiente paradigma para explicar cuál era el valor añadido gubernamental de estos órganos respecto de los Consejos.

Consecuencia de la confrontación de estas grandes etapas historiográficas fue la publicación, a mediados de los años 1990, de dos síntesis sobre juntas del Antiguo régimen. La finalidad de ambos proyectos era la misma: ofrecer un catálogo de juntas cuantitativamente pertinente para poder establecer tipologías. Así, ambos trabajos tienen en común la definición de criterios de discriminación y la elaboración de un cuadro de clasificación. Dolores Sánchez, primero, pensó su tipología a partir de la necesidad de redefinir el «deber de consejo», y fundando su análisis, en cuanto concepto jurídico medieval, en los estudios de Pérez Prendes$^{9}$. De este estudio resultó una clasificación en tres categorías: las comisiones ad hoc, las juntas ordinarias y las juntas de gobierno, lo cual venía a ser una suerte de variación sobre el tema de las relaciones entre los colegios de la polisinodia. El criterio principal era el grado de institucionalización: desde las reuniones informales de las comisiones ad hoc hasta lo que Sánchez describe como auténticos tribunales, semejantes a los propios consejos. El segundo criterio, vinculado al primero, era la duración de la actividad de las juntas, desde una absoluta brevedad - como es el caso de las numerosísimas juntas (a menudo invisibles) que desaparecían nada más resolver el asunto para el que se habían creado- hasta, digamos, cierta perennidad - la Junta de Gobierno de Mariana de Austria, por ejemplo-. Por su rigidez, este cuadro no podía abarcar la totalidad de las juntas; en realidad, para cada caso susceptible de demostrar la validez de esta clasificación se pueden alegar otros tantos que la invalidan. Sin embargo, y a pesar de los límites de esta clasificación, la propuesta de Sánchez planteaba una de las facetas

\footnotetext{
${ }^{9}$ Sánchez, 1993; Pérez-Prendes, 1972.
} 
esenciales del problema: ¿cómo caracterizar jurídicamente unos órganos que escapaban a la estructura gubernativa?

La otra clasificación fue obra de Juan Francisco Baltar ${ }^{10}$, y era doble: cronológica, por un lado, temática por el otro. Este cuadro tenía la ventaja de ser mucho más flexible $y$, por tanto, más eficaz. Pero no por ello estaba exento de limitaciones, pues se conocen numerosísimos casos de juntas que trataban de asuntos cuyas consultas procedían de varios Consejos. ¿Cuántas juntas de Guerra no fueron al mismo tiempo juntas de Hacienda? ¿Cuántas juntas dedicadas a asuntos hacendísticos no se tuvieron que entrometer también en asuntos de Castilla, de Indias o de Aragón? La verdad es que muy pocas. Pero, una vez más, esta voluntad clasificadora ponía de realce otro problema fundamental planteado por las juntas: ¿cómo encasillar, siguiendo un patrón jurisdiccional, unos órganos cuya actividad precisamente tendía a borrar las fronteras jurisdiccionales de los Consejos?

$$
* * * * * * * * * *
$$

Esta amplia herencia historiográfica resulta muy estimulante. Pero la voluntad de definir las juntas como un fenómeno, un sistema o la tendencia a encerrarlas en una tipología institucional produjo una fuerte limitación de las interpretaciones y frustró las posibilidades de ensanchar la manera de enfocarlas. La propuesta que se ofrece aquí al lector pretende abordar el problema al revés: en lugar de enfocar las «juntas de gobierno» como sistema políticamente más o menos constituido, nos proponemos analizarlas desde las incertidumbres de lo político y a través de un aleatorio "gobernar por juntas»". Puede ser que no lleguemos a ninguna definición de lo que fueron las juntas. Menos a una tipología. Pero también puede ser, y así lo esperamos, que las contribuciones aquí reunidas abran nuevas sendas para la exploración de las innumerables posibilidades que llegaron a ofrecer aquellas «reuniones» a los gobernantes.

En este dosier los autores han tratado de enfocar las funciones que podían cumplir las juntas, desentrañando los mecanismos internos de algunas de ellas con el fin de analizar de manera más pormenorizada cómo se insertaron en la polisinodia y cuáles fueron los efectos - negativos o positivos, previstos o inesperados, eficaces o contraproducentes, coherentes o contradictorios, etc.- que tuvieron sobre ella. Pues las funciones de las juntas no se limitaban a acatar las órdenes que redactaban sus mandatarios - los reyes o sus validos - sino que al mismo tiempo respondían a las necesidades del gobierno, diseñando de esta manera nuevos métodos de consulta y de acción ${ }^{12}$. Asimismo, la escasa definición

\footnotetext{
10 Baltar, 1998.

11 André, 2018a.

12 Dubet, 1999.
} 


\section{PRESENTACIÓN. «MANDO SE JUNTEN MIS MINISTROS»}

de su campo de actuación, la flexibilidad de los medios de los que gozaron, la versatilidad de sus funciones y sus objetivos resultaron ser, en ocasiones, incentivos para la búsqueda de nuevas vías de resolución, así como de nuevas formas de despacho. Desde salas adyacentes a las salas de gobierno de los Consejos o incluso desde las propias moradas de sus miembros, las juntas ampliaban el abanico de las modalidades de la toma de decisión política a la vez que, no lo olvidemos, abrían nuevas sendas hacia el ascenso socio-político.

El rechazo que siempre sufrieron las juntas por parte de grupos de consejeros influyentes, más o menos numerosos según los tiempos, estriba en que estas nuevas formas de resolver lo político se sustraían a las prácticas tradicionales - pero no por tanto inmutables - de la consulta. En las reuniones de las juntas, el saber y la experiencia se anteponían a menudo a la precedencia, la antigüedad y el honor. Pero, si por un lado eran órganos excluyentes y despertaban recelos y rivalidades, por otro representaban nuevas oportunidades de lucirse ante el rey $o$ ante sus más cercanos consejeros. Desde esta perspectiva, y a pesar de los conflictos de competencia a los que innegablemente dieron lugar las juntas, la vieja oposición entre estas y los Consejos deja de ser pertinente. Más útil sería enfocar las juntas como auténticos laboratorios gubernamentales que contribuyeron a la constante evolución y transformación de los Consejos sin que la relación entre unos y otros órganos se llegase a fijar nunca. De hecho, la historiografía suele reflejar esta complejidad al señalar cómo ciertas juntas se dedicaron a asesorar a los grandes Consejos mientras que otras se anteponían a esos últimos, siendo estas relaciones sumamente fluctuantes. Esta vertiente experimental de las Juntas se sostiene aún mejor si pensamos que la mayoría de ellas - que gran parte de la historiografía del siglo XX ha venido llamando ad hoc sin llevar tal apelación hasta sus últimas consecuencias heurísticas - eran creadas para responder a necesidades particulares y a coyunturas precisas. Pese a que muchos de los trabajos monográficos sobre juntas específicas han señalado la coyuntura político-institucional como un elemento crucial en el origen de las mismas, esta perspectiva no ha calado en los estudios más globales sobre estos colegios. Sin embargo, fueron precisamente esos orígenes siempre coyunturales los que hicieron imprescindible el dar a las juntas la mayor flexibilidad funcional y jurisdiccional posible, para que sus miembros pudieran afrontar la mutabilidad de los tiempos.

$* * * * * * * * * *$

Esta flexibilidad funcional aparece en el artículo de J. M. Díaz Blanco y A. Hernández Rodríguez dedicado a tres juntas reunidas en Sevilla en el siglo XVII. La primera junta estudiada ilustra la necesidad de recurrir a la pericia de diferentes actores, un método del que se esperaba a la vez complementariedad y eficacia. Similar a ciertas juntas encargadas de negociar, en Madrid, los servicios con el 
reino - Junta de Cortes, Junta de Arbitrios-, esta Junta tuvo por misión conseguir subsidios para la corona gracias a la colaboración de miembros de diferentes instituciones locales. En cuanto a la Junta de la Quietud, creada para poner fin a la crisis andaluza de mediados del siglo, permite echar luz sobre la forma en que las juntas, en ocasiones, se insertaban en dispositivos más amplios de resolución de los asuntos ${ }^{13}$. Sin perturbar un tipo de funcionamiento basado en recepta y recados habitual en la época, la Junta de la Quietud parece haber servido para reforzar y agilizar el despacho de las libranzas y su remisión a la Tesorería. La Junta de la Avería, finalmente, confirma dos aspectos que desde hace poco han venido apareciendo en la historiografía: la importancia de la colaboración interinstitucional y la búsqueda por los secretarios y ciertos miembros de las Juntas de una mayor fluidez en la comunicación gubernamental ${ }^{14}$. De cierta manera, la Junta de la Avería constituyó, para los años 1610, el apoyo local que le hizo cruelmente falta a la Junta para la Armada del mar océano de Felipe II en los años 1590 a la hora de movilizar, desde Madrid, todos los conocimientos y actores necesarios para la creación de una nueva armada que protegiera la carrera de Indias ${ }^{15}$. ¿Sería lícito colegir de esta última consideración el progresivo arraigo de una metodología gubernamental entre finales del reinado de Felipe II y la primera mitad del reinado de Felipe III?

El artículo de A. Jiménez Moreno, dedicado a la Junta de Coroneles, nos adentra en la gestión financiera y militar de la guerra hispano-francesa en los años 1635-1640. Surgida desde los inicios del enfrentamiento abierto entre ambas coronas, la Junta de Coroneles reunía grandes aristócratas en torno a la cuestión del reclutamiento de huestes cuyo destino era el norte de Europa. La función de este organismo consistió en potenciar la capacidad de movilización de las redes de poder de los grandes señores autorizándoles a distribuir hábitos y patentes de capitanía (en blanco) para facilitar las negociaciones con un sinfín de actores. $Y$ este es, precisamente, el otro aspecto fundamental de esta junta: la función negociadora que tuvo, siendo sus miembros capacitados para pactar con la nobleza, con asentistas e, incluso, con particulares. No es de sorprender, como lo indica Jiménez Moreno, que esta vasta estrategia de clientelismo venal llevada por toda la geografía castellano-aragonesa se realizara bajo el valimiento de Olivares. Si bien la eficacia de la Junta de Coroneles se debió a la voluntad del valido de facilitar su tarea, cabe también plantearse el cariz político de dicha estrategia.

El artículo de I. Gómez se enfrenta al caso particular de aquellas juntas formadas para dirimir los conflictos de competencia entre Consejos. Si bien la

\footnotetext{
${ }^{13}$ André, 2018b.

14 Gil Martínez, 2017.

${ }^{15}$ André, 2015.
} 


\section{PRESENTACIÓN. «MANDO SE JUNTEN MIS MINISTROS»}

Junta de competencias formada por Olivares es relativamente conocida por la historiografía, no así de las numerosas juntas ad hoc que, desde el reinado de Carlos $v$, fueron reunidas con este fin. El enfoque novedoso que propone la autora, a partir de las alegaciones jurídicas de las partes implicadas en esas contiendas, permite destacar la conflictividad entre, por una parte, el Consejo de Castilla y, por otra, los tribunales inquisitoriales y la Suprema, y sobre las modalidades de su resolución.

Uno de los puntos de mayor interés radica en que las juntas de competencias solían reunir miembros de los tribunales enfrentados. Esta situación daba a menudo lugar a un encarnizado tira y afloja entre los tribunales que, en cierto modo, prolongaban sus controversias en las propias juntas. Así, en ocasiones, el traslado del enfrentamiento desde los Consejos hacia la Junta de competencia daba lugar a una lucha de alegaciones sin desembocar en ninguna resolución -una situación que también favorecía el hecho de proseguirse la instrucción mientras la Junta no fenecía el conflicto-. En otros casos, sin embargo, se allanaban las rivalidades y se conseguían consensos políticos, más que propiamente jurídicos. Partiendo de esta lucha entre marco jurisdiccional y casuística jurisprudencial arbitrada por la necesidad política - cuando no por la urgencia-, el artículo nos invita a pensar que aquellas juntas de competencias fueron quizás un mecanismo de regulación del poder en la corte. Frente al mecanismo reformador que todos los Consejos experimentaron en varias ocasiones en el transcurso de los siglos XVI y XVII, parece emerger aquí otra modalidad, menos visible pero igualmente transformadora del régimen de competencias de la polisinodia.

Por último, el artículo de S. André hace hincapié en el dinamismo institucional de la Junta de Patrimonio de Italia entre los años 1576 y I596. Según el autor, la reunión de consejeros y secretarios en la corte con agentes del poder venidos de los territorios de la península itálica conforma la originalidad de una Junta que, de esta manera, fundamentaba el proceso de consulta en una información actualizada de las realidades locales. Las soluciones políticas -esencialmente hacendísticas - elaboradas por esta Junta, de las que el autor nos brinda unos ejemplos rescatados de una documentación fragmentaria, muestran la capacidad de sus miembros para alcanzar consensos políticos y, sobre todo, buscar soluciones novedosas. Así, el consenso político en cuanto a la necesidad de evitar realizar una numeración en el reino de Nápoles en 1590 permitió a la Junta imponer una solución pactada - la negociación de un porcentaje de aumento de la población- a los miembros del Consejo de Italia, partidarios del recuento. En cuanto a la reforma de las visitas de inspección de los oficiales de hacienda de los reinos italianos propuesta por la Junta, muestra que esta se beneficiaba del conocimiento de expertos en materia de control y de justicia. Si bien sus propuestas 
no fueron siempre adoptadas por el rey, su actividad revela un enfoque interesante de la materia política.

En resumidas cuentas, al situarse en los márgenes señalados por el derecho, las juntas aquí estudiadas no hacen sino subrayar los límites de una metodología gubernamental de tipo jurisdiccional. En estos artículos se hace patente la hipótesis de que las juntas, lejos de perturbar el sistema sinodal, facilitaron su adaptación y transformación en el tiempo. Tal hipótesis no es menor, pues implicaría sustituir a la noción de crisis del sistema por Consejo - a finales del XVI con la llegada al poder de Lerma, o a finales del XVII y principios del XVIII con la subsiguiente construcción ministerial de los Borbones- la noción de adaptación del sistema a lo contingente. De verificarse plenamente esta hipótesis en investigaciones de mayor amplitud, acarrearía no pocas consecuencias sobre la historiografía de la Administración de la Monarquía hispánica.

\section{BIBLIOGRAFIA}

André, Sylvain, «Les “Juntes”de Philippe II: expertise, bureaucratie, gouvernement», Cahiers d'études romanes, 30 2015, pp. 327-35।.

André, Sylvain, «Gouverner par juntas. Révision historiographique d'une méthode gouvernementale (Monarchie hispanique, seconde moitié du XVle siècle)», Revue d'histoire moderne et contemporaine, 65, 3, 20I8a, pp. 7-32.

André, Sylvain, «Prêts volontaires, emprunts forcés et impôt universel. La Junta grande et les aléas de la négociation au lendemain de la signature du premier servicio de los ocho Millones», e-Spania, 30, 20I8b.

Baltar Rodríguez, Juan Francisco, Las Juntas de gobierno en la monarquía hispánica (siglos XVI-XVII), Madrid, CEPC, 1998.

Barrios, Feliciano, La gobernación de la Monarquía de España. Consejos, Juntas y secretarios de la Administración de Corte (I556-I 700), Madrid, CEPC, 2015.

Benito Fraile, Emilio de, «La Real Junta del Bureo», Cuadernos de Historia del Derecho, I, 1994, pp. 49-I24.

Bercuyo, José Luis, «Notas sobre juntas del Antiguo Régimen», Actas del IV Symposium de Historia de la Administración, Madrid, INAP, 1983, pp. 93-108.

Domínguez Nafría, Juan Carlos, «La Junta de Guerra de Indias», Temas de Historia Militar. Ponencias. $2^{\circ}$ Congreso de Historia militar, Zaragoza, Estado Mayor del Ejército, 1988, p. 79-I 16.

Dubet, Anne, «Le servicio de los 8 millones (I588-I590) ou la négociation érigée en principe d'action», Ibérica, II, 1999, pp. 45-65.

Gil Cremades, Rafael, «La Junta Suprema de Estado (I787-1792)», Actas del II Symposium de Historia de la Administración, Madrid, IEA, I97I, PP. 447-467.

Gil Martínez, Francisco, La Junta de Vestir la Casa (I 636-I643). Juntas, financiación de la Corte y venalidad, Madrid, Polifemo, 2017.

Martínez Millán, José, (ed.), Instituciones y elites de poder en la Monarquía Hispana durante el siglo XVI, Madrid, Ediciones de la UAM, 1992.

Martínez Millán, José y Carlos Javier de Carlos Morales (dir.), Felipe II (I527-1598). La configuración de la Monarquía Hispana, Salamanca, Junta de Castilla y León, Consejería de Educación y Cultura, 1998.

Pelorson, Jean-Marc, «Para una reinterpretación de la Junta de Desempeño general (1603-1606) a la luz de la visita de Alonso Ramírez de Prado y de don Pedro Franqueza, conde de Villalonga», Actas del IV Symposium de Historia de la Administración, Madrid, INAP, 1983, pp. 613-627.

Pérez Prendes, José Manuel, «Bibliografía del pensamiento jurídico español», Quaderni fiorentini per la storia del pensiero giuridico moderno, I, I, I972, Pp. 449-48I.

Sánchez, Dolores María, Las juntas ordinarias: tribunales permanentes en la corte de los Austrias, Madrid, Aula abierta, 1995. 


\section{PRESENTACIÓN. «MANDO SE JUNTEN MIS MINISTROS»}

Sánchez, Dolores María, El deber de consejo en el estado moderno: las Juntas «ad hoc» en España (1474- I665), Madrid, Polifemo, 1993.

Tomás y Valiente, Francisco, Gobierno e instituciones en la España del Antiguo Régimen, Madrid, Alianza, 1982.

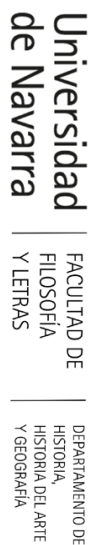

MEMORIA Y CIVILIZACIÓN 24 (202|): |3-2| [I-9] 